\title{
Spontaneous Hemoperitoneum: An Unusual Presentation of a Common Disease
}

\author{
${ }^{1}$ Raghunath BV, ${ }^{2}$ Vishwanath Bhat
}

\begin{abstract}
Intraluminal hemorrhage associated with ectopic gastric mucosa in a Meckel's diverticulum is a common presentation. However, intraperitoneal bleeding associated with Meckel's diverticulum, is considerably rare. Herein, we report a case of spontaneous intraperitoneal bleeding caused due to nonruptured, acutely inflammed Meckel's diverticulum causing erosion of one of the branches of ileocolic artery and presenting with peritonism.
\end{abstract}

Keywords: Meckel's diverticulum, Peritonism, Spontaneous hemoperitoneum.

How to cite this article: Raghunath BV, Bhat V. Spontaneous Hemoperitoneum: An Unusual Presentation of a Common Disease. J Med Sci 2015;1(2):36-37.

Source of support: Nil

Conflict of interest: None

\section{INTRODUCTION}

Bleeding complications of Meckel's diverticulum are usually due to intraluminal hemorrhage. We hereby report a case of a child aged 7 years with acute abdominal pain secondary to intraperitoneal bleeding from a Meckel's diverticulum.

\section{CASE REPORT}

A 6-year-old female child weighing $17 \mathrm{~kg}$, with no previous history of trauma or medical disorder, presented to the emergency department with acute onset of pain abdomen since 1 day and history of self limiting lower gastrointestinal bleeding 2 days back. Pain was generalized in nature and dull aching type, not associated with fever or vomiting. Clinical examination revealed a pale child with tachycardia of $102 /$ minute. There was generalized guarding in the abdomen. Per rectal examination yielded few blood clots.

\footnotetext{
${ }^{1}$ Associate Professor, ${ }^{2}$ Managing Director

${ }^{1}$ Department of Pediatric Surgery, RajaRajeswari Medical College, Bengaluru, Karnataka, India

${ }^{2}$ Department of Pediatric, Radhakrishna Nursing Home Bengaluru, Karnataka, India

Corresponding Author: Raghunath BV, Associate Professor Department of Pediatric Surgery, RajaRajeswari Medical College, Bengaluru, Karnataka, India, e-mail: bvraghunath9@ gmail.com
}

Investigations revealed hemoglobin: A $6.5 \mathrm{gm} \%$ and total leukocyte count of 13,800. A ultrasound of the abdomen suggested mild ascites with few dilated bowel loops. Appendix could not be commented upon.

After initial resuscitation with IV fluids and one unit packed cell transfusion, child was taken up for emergency laparotomy with a provisional diagnosis of a ruptured Meckel's diverticulum. Abdomen was opened by a right supraumbilical transverse incision. Intraoperatively, approximately $150 \mathrm{mg}$ of fresh blood clot was seen, mainly in the right iliac fossa, which was evacuated. An acutely inflamed, nonperforated Meckel's diverticulum was seen adhered to the ileo caecal junction. On gently separating the adhesion, an arterial spurter from one of the branches of the ileocolic artery was seen which was ligated. Resection of the segment of intestine containing the diverticulum with anastomosis was done. Abdomen was closed without a drain.

Postoperative course was uneventful. Child was started on feeds from postoperative day 4 and was discharged on day 6. Histopathology of the diverticulum revealed gastric mucosa with acute inflammation in the diverticulum.

\section{DISCUSSION}

Meckel's diverticulum, a remnant of the vitello (Fig. 1) intestinal duct is seen in $2 \%$ of the general population. Though it is usually discovered as an incidental finding during laparotomies for other reasons, it can present

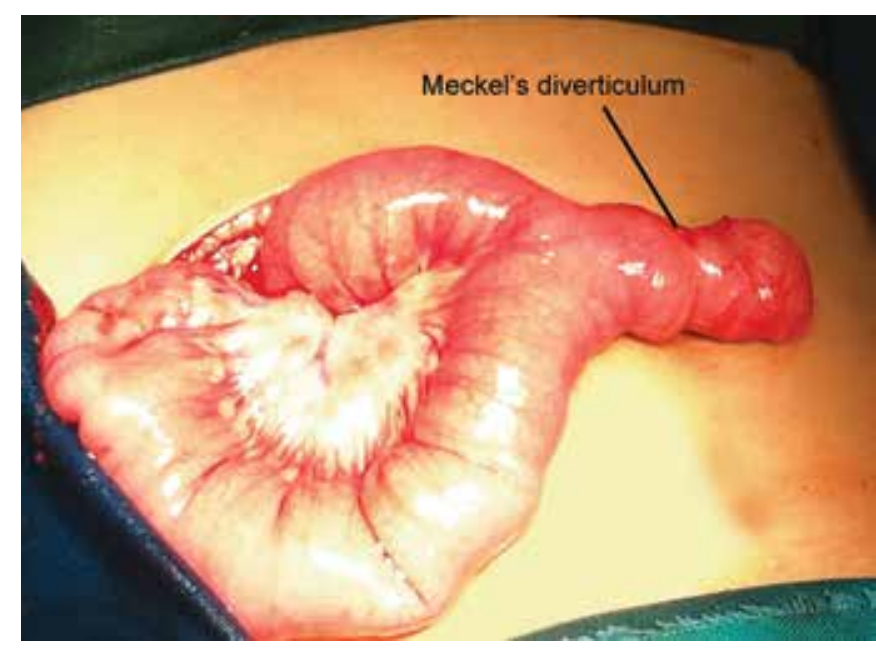

Fig. 1: Meckel's diverticulum showing site of adhesion to the ileocolic mesentery 
with complications. The most common complications include diverticulitis, intraluminal bleeding leading to chronic anemia or acute gastrointestinal bleeding, perforation leading to peritonitis, acute intestinal obstruction secondary to bands, may act as the lead point for intussusceptions.

Extraluminal bleeding from a Meckel's diverticulum is relatively rare. Few articles report such an event in children. ${ }^{1,2}$

The commonest cause for hemoperitoneum in a child with Meckel's diverticulum is peptic ulceration followed by perforation and bleeding. Other described mechanisms include tearing of the mesodiverticular bands which anchor the tip of the diverticulum to the anterior abdominal wall in both traumatic ${ }^{3}$ and atraumatic ${ }^{4}$ settings. Bleeding from a torn Meckel's mesentery has also been described. ${ }^{5}$ Burt et $\mathrm{al}^{6}$ described a case of hemoperitoneum resulting from an inflammed, nonperforated Meckel's diverticulum containing no ectopic tissue. They attributed the bleeding to inflammation disrupting the diverticulum's vascular supply.

In our child, the bleeding resulted from local inflammation and erosion of a branch of ileocolic artery. To the best of our knowledge, this cause for bleeding has not been reported so far. We wanted to share our experience regarding this rare cause for bleeding and also to highlight that any child with lower GI bleed and clinical signs of peritonism, a bleeding Meckel's diverticulum has to be considered.

\section{REFERENCES}

1. El-Hussuna A, Zeb A, Mogensen AM, Naver L. Perforation of Meckel's diverticulum with intra-abdominal hemorrhage and periappendicular inflammation. Ugeskr Laeger $2009 \mathrm{Dec}$ 7;171(50):3676-3677.

2. Jelenc F, Strlic M, Gvardijancic D. Meckel's diverticulum perforation with intra-abdominal hemorrhage. J Pediatr Surg 2002;37(6):E18.

3. McAneny D, Rapo SE, Grindlinger GA. Traumatic hemoperitoneum due to a Meckel's meso diverticular band: a case report. J Trauma 1989;29(2):261-262.

4. Velalcott KD. Haemoperitoneum due to Meckel's diverticulum. J R Coll Surg Edinb 1981;26(2):89-90.

5. Jaffray CE, Durham RM, Flint L. Post traumatic hemoperitoneum from disrupted vessels of a Meckel's diverticulum. Surg Rounds 2003;26(10):481-482.

6. Burt BM, Tavakkolizadeh A, Ferzoco SJ. Meckel's Hemoperitoneum: a rare case of Meckel's diverticulitis causing intraperitoneal hemorrhage. Digestive Diseases and Sciences 2006;51(9):1546-1548. 